\title{
Research on the Teaching of Integrating EDA Technology into Digital Electronic Technique
}

\author{
Xiaojing Li, Xiaofei Li and Rongli Wang
}

School of electrical engineering, Tianjin University of Technology, Tianjin, 300384, China

iobox@126.com

Keywords: EDA; Digital Electronic Technique; Integrate; Teaching Reform

\begin{abstract}
EDA Technology is in the ascendant which performs more and more important functions of the higher education of electricity. A comparatively integrated teaching system connecting the theory about practice has been established though introducing EDA into the course of Digital Electronic Technique. The application of EDA technology is not only a good method to improve the quality and level of teaching, but also an effective tool to develop the abilities of students in thought, practice and innovation. Several aspects are discussed in this paper such as theory teaching, practice teaching, network teaching, course design, assessment methods, teachers' function, extracurricular practice, graduation project, etc.
\end{abstract}

\section{Introduction}

EDA [1] (Electronic Design Automation) is broad, content rich. The wider application of EDA is based on PLD (Programmable Logic Devices) [2] in teaching and technology popularization level. At present, EDA is becoming the main way and the important means of modern digital electrical systems design.

PLD has been widely used in digital systems as the mainstream of design device. FPGA (Field Programmable Gate Array) can refactor its internal hardware structure and working methods by EDA technology. Therefore, the hardware design is as convenient as software design, which is a revolutionary change in the field of electronic circuit design.

The digital electronic systems rely on EDA software, a wide variety of digital logic module and hardware description language, appropriate experimental equipment based on FPGA, and thus to carry on the design of digital. The advantages of these digital electronic systems are simple, reliable, low-power and fast. So this method has been widely used in the field of electronic design.

\section{Curriculum Reform}

"Digital electronic technique" is one of the important basic curriculums of electrical majors, which focusing on the analysis, design and application of digital circuit [3]. The reform of teaching contents and methods by introducing EDA to the course was implemented in order to improve the electronic design and engineering practical ability of students. In teaching practice, two natural classes including about 75 students were chosen as experimental classes. Then the teaching system and contents were reformed such as improving teaching methods, adjusting teaching structure, optimizing teaching contents. As a result, the design concept of EDA was integrated indeed into every teaching link. Hence the teaching effect of course had got the overall improvement and the students' abilities were improved on practice, innovation and engineering consciousness. The following is how to improve the teaching quality of digital electronic technology course by EDA technology with authors' experience in the teaching practice.

\subsection{Theoretical Teaching.}

The effect of traditional theoretical teaching is not ideal because teacher was the subject and students were the object of knowledge infusing. After Reforming, EDA knowledge was added to small-class teaching and integrated the process of the original teaching plan. The method that research and engineering elements' integrating in classroom instruction made students closer to the 
engineering practice. All of these measures are benefit to cultivate students' interest in scientific research and lay the foundation for the students' future work and studies.

\subsubsection{The Introduction of EDA}

The application of EDA in digital electronic technology was introduced by the schematic diagram method of Quartus II for the students had not the basic knowledge of hardware description language in early study. The abstract theoretical knowledge of this course was presented by scientific and intuitive methods, such as transient, synchronous and asynchronous phenomena. So various characteristics of the circuits were analyzed with a simple way and the abstract theory was visualized, complex circuits were pragmatized. Therefore this practice was not only good to avoid tedious teaching, but also for students' interest in learning and understanding of the theoretical knowledge.

\subsubsection{The Application of EDA}

"Digital electronic technique" course involves a lot of integrated circuit chips, which structure and principle are similar. So it was not worth the effort to focus the use of specific chips. As a result, several typical chips were introduced and the rest of chips may be comprehended by analogy for the students to improve their self-study and application ability. Moreover, cumbersome abstruse theory explaining was replaced by EDA software for auxiliary teaching in class. This measure avoided complex circuit analysis process and strengthened the intuition and the sense of reality. At the same time, EDA was used to build some actual circuits. For example, 555 timer was presented by the doorbell and so on. This method made students understanding the knowledge in class was not the abstract circuits but the actual products. Thus they may find the connection between the theory and practice.

\subsubsection{PLD and VHDL}

VHDL (Very High Speed Integrated Circuit Hardware Description Language) and digital electronic system design were emphasized for some class hours in the teaching process of "programmable logic devices". Programming statements teaching item by item was replaced by a combination of some examples to clarify the most essential parts and core for VHDL language teaching. This way enable students grasp effectively and put it into practice in a short time[4].

\subsection{Practice Teaching.}

"Digital electronic technique" is a strong practicing course. So the practice teaching mode focusing on cultivating the innovation ability was built by student-centered thought and practice teaching idea reformation[5].This method of work urge the students to put new knowledge, new technology, new means into use. Therefore the practical ability and innovation consciousness of students were improved greatly. The infinite imaginary space was presented for students at the same time. Since the practice teaching is the most important of the teaching reform for digital electronic technology course, the specific measures are introduced as follows.

\subsubsection{Revision of Practice Teaching Files}

The experiment course of digital electronic technology was set up as the lesson alone in our university. The class hours became 24 to 32 and the comprehensive design of EDA experiments were increased in the syllabus. At the same time, a simple practical tutorial was written grounded on realities of situation for our university. Several parts were added to the teaching contents based on traditional experiments in this textbook, such as the application of Quartus II, VHDL hardware description language, FPGA experimental systems and experimental projects.

\subsubsection{Strengthening laboratory Construction}

Several methods had been implemented in order to provide a favorable practical environment and opening independent practical teaching services for students such as building opening experimental teaching platform, improving the laboratory's construction of comprehensive, digital and network resources. Meanwhile, some measures were put into practice to ensure the quality of experimental teaching including establishing the monitoring and evaluation mechanism of experimental teaching quality, strengthening the organization and management of open experimental teaching. 


\subsubsection{Coordination of Practice and Theoretical Teaching}

Some teaching contents (e.g. the use of Quartus II and FPGA experimental system) were put into practice teaching since students seldom had chances to operate personally in theory class [6]. In this way, the students can master the usage of equipment quickly by accessing and actually operating. Therefore this method not only saved teaching time, but also improved the students' learning interest and practical ability.

\subsubsection{Coordination of Practice and Theoretical Teaching}

The traditional experiments could cultivate students' basic practice skills for they were the foundation experiments by discrete components. So this mode was essential in basic training stage. However, the mode was not conducive to students' freedom and creative ability. As a result, it was reduced in the teaching schedule. Then the weight of comprehensive design experiments [7] was increased which focusing on programmable technology. Then students may master the use of EDA tools to complete the design of FPGA circuit. Moreover, this mode was benefit to further strengthen the operation ability and comprehensive practice ability. Students are required to design the schemes and program under the guidance of teachers. These design included mainly preparation, input, processing (compilation, synthesis and adaptation), verification (function and timing simulation), downloading the programming file (device configuration), and hardware testing and other aspects [8].

\subsection{Network Teaching.}

The network teaching platform was created in order to expand the space of communication between teachers and students. Network teaching had become a powerful complement to classroom teaching for its advantages such as large amount of information, strong interactivity, and wide coverage, breaking through time and space constraints of traditional teaching. Many columns were set on the platform to fully meet the needs of students' learning and communication. For instance, " introduction of course ", "electronic teaching plan (ETP)", "examples and exercises "," download space"," forum of teachers and students "," troubleshooting "," Frequently Asked Questions (FAQ) ". In addition, the platform was linked to the domestic and foreign famous EDA website and the latest developments of EDA were published in real time. All of these methods enable students to understand the new development trend of technology and enhance the ability to obtain new knowledge.

\subsection{Curriculum Design.}

Curriculum design was provided a good opportunity for students as an important part of education practice. The advantages included integrating theory with practice, test of knowledge, deepening understanding, widening thinking, learning new knowledge. And the aim of it was to cultivate students mastering the basic design method of digital electronic systems, preliminary design ability, then the students can solve practical problems independently and lay the foundation for the research and development of electronic products using the knowledge and practice skills, which were the comprehensive application of PLD,EDA software and hardware description language.

The specific implementation process was described as follow. Firstly, the design topics were determined by teachers' recommending or students self-designed. Secondly, task statements were issued by teachers. Then the students were required to finish the design, simulation and hardware testing independently in two weeks. In addition, complete design reports and defense were submitted and held after realizing the requests of task statements. This process promoted students' comprehensive practical ability greatly since they had the full design experience from topic selection, investigation, scheme making, software design, and hardware debugging. This study mode was very popular from the feedback of students. They hoped to have more similar training opportunities. The students' innovation ability and potential presented in the process were unexpected for us. That was to say that the right guidance of teachers will do good to cultivate the students' ability.

\subsection{Assessment Modes.}

The performance appraisal is an important means to test the quality of teaching. To evaluate the cultivating effect of students should focus on using diversified evaluation methods to estimate the 
practical application of knowledge and practice ability assessment. That is to say, the traditional mode of depending only on the exam scores was unsuitable.

Three parts of "digital electronic technique" course were all independent-based classes including theoretical teaching, practice teaching and curriculum design. The appraisal of theoretical teaching was mainly based on written test, which accounted for $80 \%$. Then the attendance and homework accounted for $20 \%$. As for practice teaching, the students were required to finish the experiments independently in usual time. The usual-time mark of student was appraised by the performance and experiment reports among the process of practice, which accounted for $40 \%$. Students were provided a change to draw an examination question from several synthetic and designing subjects and complete within the stipulated time at the last time of practice teaching. Then their grades were given depended on the operate ability and test results, which accounted for $60 \%$.

Curriculum design evaluation were examinated according to the students' circuit design ability, operate ability, innovation ability, design reports and defense. Among them, scheme design accounted for $20 \%$, completing effect accounted for $30 \%$, reports accounted for $30 \%$, and defense accounted for $20 \%$.

\subsection{The Role of Teachers.}

There were new and higher requirements for teachers of "digital electronic technique" because it was a new element for this basic professional course.

First of all, teachers for theoretical and practice teaching were required to understand both the theory and the operation. "Digital electronic technique" was the excellent course in our university and all of the teachers had not only profound theoretical foundation but also highpractical ability, who had been engaged in the front-line teaching. Each teacher was responsible for his class ' theoretical, experiment teaching and curriculum design. This mode ensure the continuity and quality of teaching.

Secondly, teachers must be active participators in the researches related to EDA to improve their professional skills. Then they could combine research results with teaching contents. Therefore the best teaching effect would be gotten by introducing the latest technology achievements to teaching, constant practices and summaries.

Finaly, it was the source of teaching reform for communication, learning and reference of counterparts. Several measures were implemented, such as sending teachers to the domestic colleges and universities, attending to the national training for excellent courses, keeping in touch with domestic and foreign colleges and universities. All of these methods could update the concept of teachers and expand the field of vision.

\subsection{Extracurricular Practice.}

College and social classrooms were combined in the process of educational reform.A series of activities were organized such as extracurricular visit, technological innovation and others. Students were teached hierarchically and individually in accordance with their aptitude. As a result, EDA Teaching and students' practice in scientific and technological activities were strengthened closely.

Students were encouraged to develop extracurricular interest groups to research problems in learning and design electronic works in cooperation.

At the same time, innovative laboratories were provided as a practice platform for top students to further show their individual talents. These lab were open all day and managed by the students themselves. A series of extracurricular scientific and technological activities were carried out guided by some teachers with actual engineering experiences. So a large number of contestants with a certain basis were delivered for electronic design contest and other activities. Some of the best students may participate in scientific research under the guidance of teachers to complete some sub projects or functional modules.

In addition, students were encouraged to research and write papers or declare the college students' innovative experiment project and other innovation projects. These methods were all benefit for the students' consciousness of engineering and quality. 


\subsection{Graduation Project.}

The graduation projects in the past usually remained in the discussion and analysis of theories, then debuging and verification could not be done actually. As a result, the effects of graduation design was diminished. In recent years, a series of graduation projects based on FPGA were carried through combining with EDA technology. The students' professional knowledge in 4 years was stringed together to improve their comprehensive ability and made a full preparation for their future work in the society. The fact in practice reflected that the foundation in learning "digital electronic technique" played a big role in the in the process of graduation design.

\section{Conclusion}

In this paper, the teaching reform was described that introducing EDA to "digital electronic technique" course. This reform could not only improve the efficiency and quality of teaching, but also broaden students' views, aroused students' interest, enthusiasm and initiative. Therefore students' understanding of the theory was deepened and their practice and innovation ability were strengthened. It laid certainly the foundation for the subsequent courses and professional work of these students.

It still has a long and challenging journey ahead of us for higher education. We should carry out the teaching research and explore the law of teaching with high responsibility and attention on the development of the latest technology in the world. As a result, more high quality graduate students would be cultivated for the society and the quality of higher education may be improved.

\section{Acknowledgment}

We thank our colleagues from school of electrical engineering, Tianjin University of Technology, and we appreciate the help from our leaders and colleagues.

Project Fund: Tianjin Board of Education talent program, “Tianjin universities outstanding young teachers funding” (401007008); Tianjin University of Technology teaching fund, "The research of opening for innovative laboratory” (YB11-66); Tianjin University of Technology teaching material fund ( JC 15-06).

\section{References}

[1]. WANG Yanchun, Discussion on Integrating EDA Technology with Electronic Technology Curriculum[J], Experiment Science \& Technology, 2009, 7(6), P89-91(In Chinese).

[2]. LI Nan, LIANG Jianfang, On improvement of digital circuit course from teaching programmable logic device (PLD)[J], Journal of Dalian Naval(In Chinese).

[3]. KANG Huaguang, ZOU Shoubin, QIN zhen, Fundamentals of Electronic Technique (Digital)[M]. Beijing: Higher Education Press, 2008.1(In Chinese).

[4]. ZHU Yidan, Practice of Teaching Reform for the VHDL Design[J], Journal of EEE, 2007, 29(2), P22-23 (In Chinese).

[5]. LUO Jun, Discussion on the reform of the course, electronic technology[J], Journal of Chongqing College of Education, 2008, 21(6), P30-32 (In Chinese).

[6]. LI Jianxia, Exploration of integrated design experimental teachi ng methods[J],Research in Tesching, 2009, 32(3), P62-64 (In Chinese).

[7]. Tang Hongshan, Lu Mingda, VHDL and Digital Circuit Teaching[J], Journal of North China Electric Power University, 2002, 29(5), P174-177 (In Chinese).

[8]. SHAO Kai, LIANG Yan, Combination of EDA technique and digital circuit experiment teaching $[\mathrm{J}]$, Journal of Chongqing University of Posts and Telecommunications(Natural Science), 2006, 27 (6), P109-110 (In Chinese). 